\title{
Ретроспективный анализ степени изменчивости чувствительности полевых изолятов кокцидий к наиболее часто применяемым кокцидиостатическим препаратам
}

Бирюков И.М., научный сотрудник отдела паразитологии

Симонова Е.А., младший научный сотрудник отдела паразитологии

Всероссийский научно-исследовательский ветеринарный институт птицеводства (ВНИВИП) - филиал ФГБНУ ФНЦ «Всероссийский научно-исследовательский и технологический институт птицеводства» РАН

Аннотащия: Представлены результаты ретроспективного анализа состава полевых итаммов эймерий, быделенных 622 птицебодческих хозяйствах РФ 6 2016-2019 г2., с учетом проябления признакоб адаптации к наиболее часто применяемым кокцидиостатическим препаратам. Из образиоб помета от птицепоголовья различного возраста, предоставленного хозяйствами, быделяли и идентифииировали культуры эймерий, определяли их видовой состав. Эймериостатическую активность препаратов изучали при заражении 14-дневных иыплят быделенными полебыми итаммами. Анализ бидового разнообразия эймерий показал снижение за изучаемый период частоты моновидовых инбазий и побышение частоты смешанных инбазий 2 или 3 бидами, что блияет на степень изменения адаптации к эймериостатикам. Установлено, что все исследованные образиы полебых итаммов эймерий имели ту или иную степень устойчивости к тестируемым химиопрепаратам, несмотря на то, что $\mathrm{c}$ 2019 г. фиксируется постепенное снижение адаптации к некоторым из них. Полученные результаты указывают на наличие как перекрестной адаптации, так и групповой (множественной) устойчивости, что соответствует глобальной тендениии роста феномена устойчибости эймерий к кокцидиостатическим препаратам.

Ключебые слова: кокиидиоз, эймерии, антикокиидийные препараты, эймериостатики, цыплята, Eimeria tenella, E. acervulina.

Введение. Заболевания желудочно-кишечного тракта наносят значительный ущерб развитию мясного и яичного птицеводства, влияя как на зоотехнические показатели этих направлений по отдельности, так и на общее благосостояние птицеводческой отрасли в целом.

Несмотря на всю важность угрозы, вызванной кишечными заболеваниями, часто бывает сложно определить первоисточник поражения кишечника изза воздействия многочисленных факторов различной этиологии. На сегодняшний день описан ряд наиболее важных кишечных па- тогенов, наносящих урон птицеводческой отрасли [1].

Наряду с бактериальными патогенами, проблему кокцидиоза можно без преувеличения считать одной из наиболее важных с экономической точки зрения, особенно для бройлерного производства. Патогенное влияние кокцидийных агентов связано с падежом, вынужденным убоем заболевшей птицы, неоправданным расходом кормов и т. д.

Из семи видов кокцидий наибольшую угрозу для птицеводства представляют Eimeria acervulina, E. maxima, E. tenella, E. necatrix, которые имеют феномен локаль- ного паразитирования (развитие в определенном отделе кишечника), с присущими для каждого вида патоморфологическими отличиями и клиническими проявлениями [2]. Кроме того, интродукция кишечника эймериями является главным фактором развития некротического энтерита [3]. Такая ассоциация приводит к нарушению целостности эпителиального слоя кишечника, возникновению кровотечений и индукции мукогенного ответа хозяина на кокцидиальную инфекцию, что в целом обеспечивает благоприятные условия для колонизации кишечника Clostridium perfringens [4]. 
В связи с этим важное место в технологическом процессе выращивания птицы должна занимать профилактика эймериоза. Борьба с этим инвазионным заболеванием до сих пор остается актуальной проблемой.

Наиболее эффективными в борьбе с кокцидиозом оказались кокцидиостатические препараты. Основной сложностью использования этих препаратов в условиях промышленного птицеводства является относительно быстрое формирование у кокцидий адаптационной способности к лекарственным веществам. Формирование такой устойчивости в производственных условиях наблюдается часто и в большинстве случаев напрямую зависит от интенсивности применения лекарств. Определить рациональный срок использования того или иного лекарственного средства в производстве на основании лабораторных исследований трудно. Однако ориентировочно можно предвидеть сроки, в течение которых кокцидиостатические препараты будут эффективны для профилактики кокцидиоза.

Как отмечают многие авторы, в зависимости от химической природы соединений и штамма кокцидий, временной промежуток развития адаптации кокцидий к препаратам неодинаков, а адаптация может сохраняться на неопределенный срок. Например, адаптация к клопидолу или препаратам хинолонового ряда происходит значительно быстрее, это позволяет ветеринарным специалистам быстро выявить ее и взять под контроль. И, наоборот, к ионофорным антибиотикам, ампролиуму, никарбазину и к ряду других противококцидийных препаратов резистентность может формироваться длительное время [5].

В 1965 г. Всемирная Организация Здравоохранения ввела опре- деление лекарственной устойчивости, как способности патогенов выживать и размножаться, несмотря на введение лекарственного средства в дозах, равных или превышающих рекомендованные. Устойчивость кокцидий к химиопрепаратам можно сгруппировать следующим образом: приобретенная адаптация - резистентность, возникающая в результате генетической передачи феномена адаптации последующим поколениям паразита; перекрестная адаптация - способность кокцидий развивать устойчивость к препаратам, состоящим в одной химической группе, с одинаковым механизмом действия; и групповая (множественная) устойчивость - это адаптация кокцидий к нескольким лекарственным средствам с различными механизмами действия [6].

На данный момент исследователей и практиков в большей степени интересует другая проблема - снятие феномена адаптации, т.е. чем или как можно предупредить развитие устойчивости кокцидий к кокцидиостатическим препаратам, а также поиски способов блокировки возникновения этого феномена у последующих поколений паразита.

Цель работы - провести ретроспективный анализ состава полевых штаммов эймерий, выделенных из птицеводческих хозяйств, с учетом проявления признаков адаптации к наиболее часто применяемым кокцидиостатическим препаратам.

Материал и методика исследований. Материалом для проведения данной работы послужили образцы подстилочного и бесподстилочного помета от птицепоголовья разных возрастных групп, предоставленные птицеводческими хозяйствами РФ. Проведен ретроспективный анализ результатов исследования на чувствительность к кокцидиостатическим препаратам образцов из 22 птицехозяйств РФ, начиная с 2016 и заканчивая 2019 г.

Из полученных образцов выделяли и идентифицировали культуру эймерий методом фракционирования в сочетании с методом Фюллеборна. Исходя из общепринятой морфологической и биометрической диагностики ооцист кокцидий и степени патологоанатомических поражений кишечника восприимчивой птицы, определяли видовой состав кокцидий.

Эймериостатическую активность препаратов изучали при однократном заражении выделенными полевыми штаммами эймерий в дозах $\mathrm{LD}_{50-75}$ 14-дневных цыплят, выращенных в условиях, препятствующих самопроизвольному заражению эймериями.

В каждом опыте птицу делили на чистый и зараженный контроль и на группы, получавшие лекарственный препарат в сочетании с комбикормом.

Птицу опытных групп и одну из контрольных однократно заражали полевыми штаммами эймерий. Препараты давали птице подопытных групп в сочетании с комбикормом в течение 11 суток, начиная за день до заражения. Всю птицу взвешивали перед началом опыта и по его окончанию, на 11 сутки.

В ходе опытов были протестированы кокцидиостатические препараты, относящиеся к следующим классам:

- Препараты, полученные путем химического синтеза: клопидол (КЛОПИдОЛ), робенидин 6,6\% (РОБ), никарбазин (НИК), диклазурил (ДИК), декоквинат (ДЕКОК).

- Ионофорные кокцидиостатики: моновалентные ионофоры - салиномицин 12\% (САЛ), монензин (МОН); моновалентный гликозидный ионофор - 


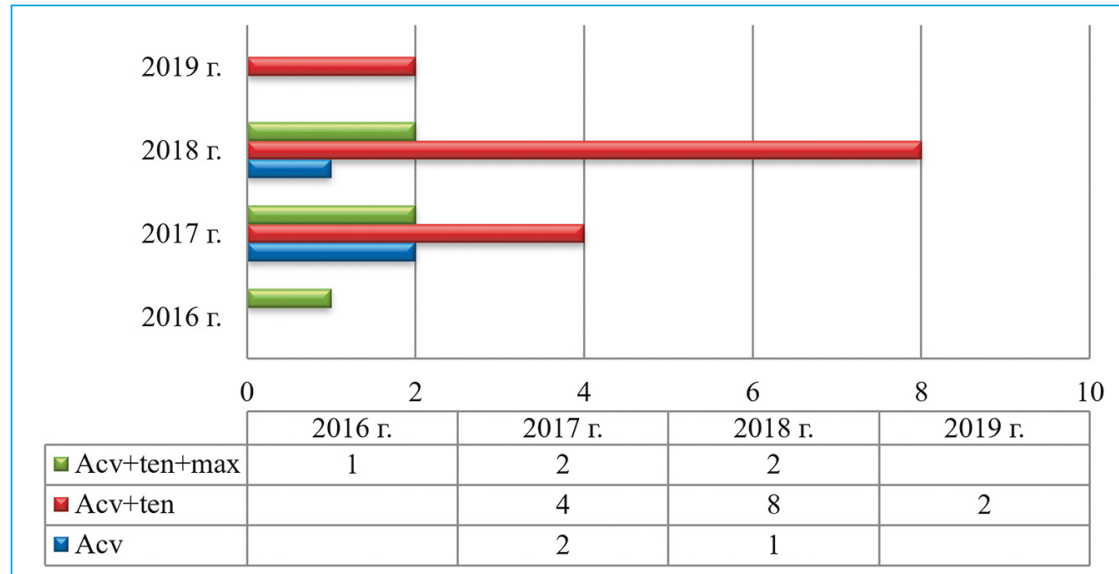

Рисунок 1. Видовое многообразие и корреляция полевых штаммов эймерий

мадурамицин (МАД); двухвалентный ионофор - ласалоцид натрия (ЛАС).

- Синергетические (комплексные) смеси - наразин/никарбазин (НАР/НИК), мадурамицин/ никарбазин (МАД/НИК).

Основными критериями определения активности лекарственных средств в отношении кокцидий являются различия по приросту живой массы и процент сохранности поголовья в контрольных группах и группах с препаратами. Эти показатели отображаются в противококцидийном индексе (ПКИ), предложенным и усовершенствованным М. В. Крыловым [7].

Максимально возможный противококцидийный индекс для препарата, не стимулирующего дополнительный прирост живой массы, составляет 200 баллов. Если активность тестируемого препарата ниже 120 балов, а также наблюдается гибель птицы в подопытной группе, то эймериостатическая эффективность препарата является низкой, что указывает на высокую адаптацию кокцидий к препарату. При ПКИ в пределах 120-160 баллов можно считать, что химиотерапевтическая активность для тестируемого препарата является умеренной, а у эймерий проявляется частичная адаптация. В том случае, если активность препарата 160 баллов и выше, его относят к высокоактивным и считают, что у паразита отсутствуют признаки адаптации к данному химиопрепарату.

Результаты исследований и их обсуждение. Моновидовая культура E. acervulina была выделена в 3 хозяйствах. В 14 хозяйствах выделили смесь полевых штаммов E. acervulina и $E$. tenella. В 5 хозяйствах обнаружили поливидовую культуру, представленную смесью E. acervulina, E. tenella и E. maxima. Видовое многообразие полевых штаммов эймерий представлено на рис. 1. Видно, что, начиная с 2017 г. отмечается превалирование двуви- довой смеси культур эймерий E. acervulina и E. tenella.

частота встречаемости $E$. acervulina при моновидовой инвазии уменьшилась вдвое в 2018 г. или не наблюдалась, как 2019 г. Выделение поливидовой культуры, представленной тремя видами эймерий E. acervulina, E. tenelIa, E. maxima, увеличилось до двух изолятов в 2017 и 2018 гг. по сравнению с 2016 г.

На рис. 2 показаны результаты исследований по антиэймериозной активности химиопрепаратов в течение периода с 2016 по 2019 гг.

До 2018 г. все тестируемые препараты, кроме никарбазина, имели среднюю антиэймериозную активность, что говорит о частичной адаптации полевых штаммов эймерий к кокцидиостатическим препаратам. Никарбазин проявил высокую антиэймериозную активность, что свидетельствует об отсутствии адаптационных признаков.

За 2019 г. салиномицин 12\%, мадурамицин, робенидин 6,6\%, диклазурил, декоквинат, сочетание мадурамицин/никарбазин перешли из группы препаратов средней активности в группу вы-

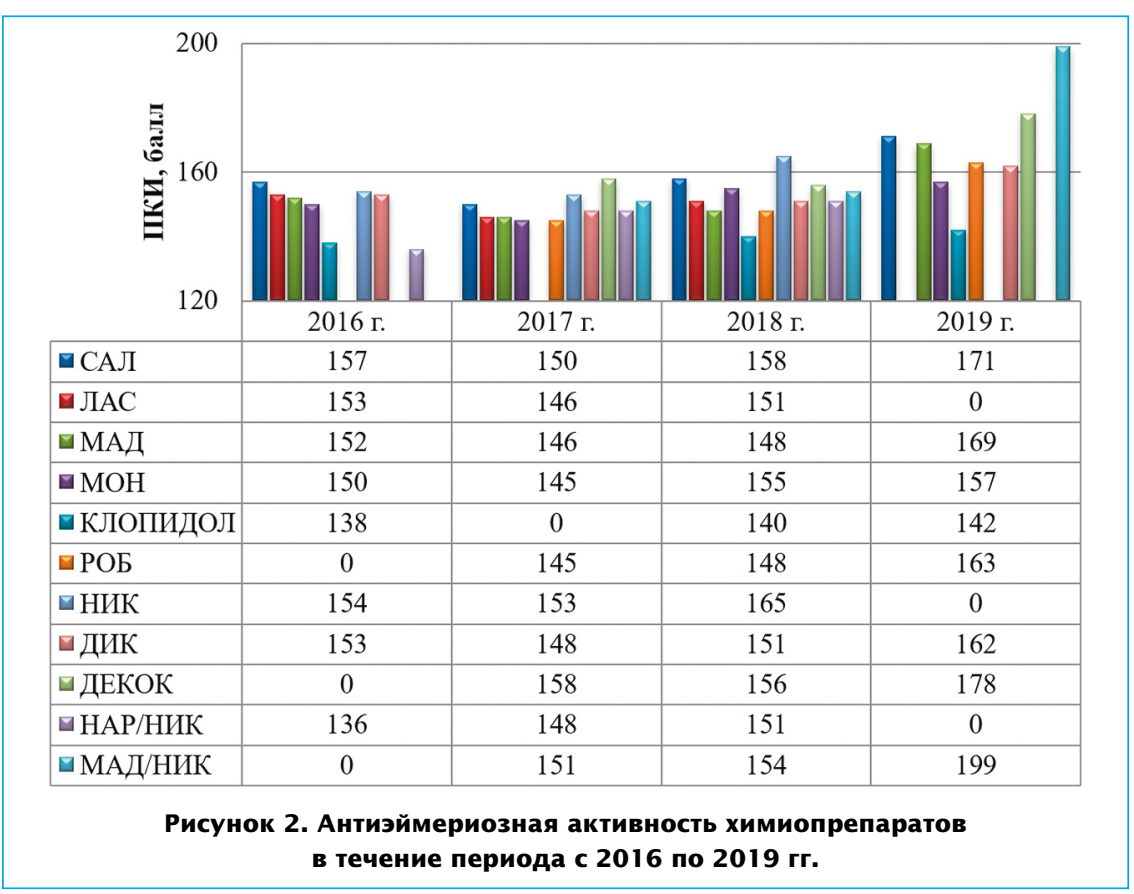


сокоактивных препаратов и, тем самым, показали восстановление чувствительности к ним у полевых штаммов эймерий.

Заключение. Проведенный ретроспективный анализ показал снижение периодичности регистрации моновидовой кокцидийной инвазии, как основного аспекта заболевания, все чаще регистрируется распространение двух или более видов эймерий, что также будет влиять на степень изменения адаптации к эймериостатикам.

Установлено, что все исследованные образцы полевых штаммов эймерий имеют ту или иную степень устойчивости к тестируемым химиопрепаратам, несмотря на то, что с 2019 г. фиксируется постепенное снижение адаптации к некоторым препаратам. Устойчивость паразита развивается в течение определенного времени, которое зависит от механизма действия химиопрепарата, и не одномоментно (скачкообразно), а постепенно. Стоит также отметить, что у разных видов кокцидий развитие резистентности к эймериостатикам вырабатывается неодинаково.

Результаты исследований указывают на наличие как перекрест- ной адаптации, так и групповой (множественной) устойчивости, что соответствует глобальной тенденции роста феномена устойчивости эймерий к кокцидиостатическим препаратам.

Основным залогом успеха восстановления лекарственной чувствительности у кокцидий является контроль изменения степени адаптации паразита к применяемым препаратам. Это позволит своевременно скорректировать план химиотерапевтических мероприятий, направленных на борьбу с инвазией, что, в свою очередь, позволит минимизировать потери от кокцидиоза.

\section{Литература}

1. Ter Veen C., de Bruijn N.D., Dijkman R., de Wit J.J. Prevalence of histopathological intestinal lesions and enteric pathogens in Dutch commercial broilers with time // Avian Pathol. - 2017. V. 46. - P. 95-105.

2. Györke A., Pop L., Cozma V. Prevalence and distribution of Eimeria species in broiler chicken farms of different capacities // Parasite. - 2013. - V. 20. P. 50.

3. Assis R.C.L., Luns F.D., Beletti M.E., Assis R.L., Nasser N.M., Faria E.S.M.,
Cury M.C. Histomorphometry and macroscopic intestinal lesions in broilers infected with Eimeria acervulina // Vet. Parasitol. - 2010. - V. 168. - P. 185-189. 4. Forder R.E., Nattrass G.S., Geirer M.S., Hughes R.J., Hynd P.I. Quantitative analyses of genes associated with mucin synthesis of broiler chickens with induced necrotic enteritis // Poult. Sci. - 2012. - V. 91. - P. 1335-1342.

5. Хованских А.Е. Кокцидиоз сельскохозяйственной птицы / А.Е. Хованских, Ю.П. Илюшечкин, А.И. Кириллов. - Л.: Агропромиздат, 1990. - 150 с.

6. Abbas R.Z., Iqbal Z., Blake D., Khan M.N., Saleemi M.K. Anticoccidial drug resistance in fowl coccidia: the state of play revisited // World's Poult. Sci. J. - 2011 . - V. 67, No 2. - P. 337-350. 7. Бирюков И.М. Сравнительная эффективность применения в птицеводстве зарубежных и отечественных кокцидиостатиков с идентичными действующими веществами // Птицеводство. - 2020. - №10. - С. 63-65.

\section{Для контакта с авторами:}

Бирюков Илья Михайлович

E-mail: i_biryukov88@mail.ru

Симонова

Екатерина Александровна

E-mail:

vetsaneco.vnivip@yandex.ru

\title{
Retrospective Analysis of the Composition of Eimeria Field Isolates and the Dynamics of Their Sensitivity to the Commonly Used Coccidiostatics in 2016-2019
}

\author{
Biryukov I.M., Simonova E.A. \\ Federal Scientific Center "All-Russian Research and Technological Institute of Poultry" \\ of Russian Academy of Sciences
}

\begin{abstract}
Summary: A retrospective analysis of the biodiversity of field strains of Eimerias isolated from 22 Russian poultry farms in 2016-2019 and dynamics of their adaptation to the commonly used coccidiostatics was performed. The eimeriostatic activity of the drugs was studied by the infection of 14-day chicks with isolated field strains. The analysis of the biodiversity of the field strains evidenced that between 2016 and 2019 the incidence of single species invasions decreased while the occurrences of the mixed invasions by 2 or 3 species increased; these combined invasions evidently contributed to the rate of the resistibility to coccidiostatics. All studied field strains featured certain degree of tolerance toward common coccidiostatics though after 2019 the trend to lower adaptation of the Eimerias to certain drugs was registered. Our results evidenced the presence of the adaptation to certain classes of the coccidiostatics and multi-drug resistibility to the drugs from different classes. These findings are in agree with the worldwide trend of the increased multi-drug resistibility of the Eimerias to the coccidiostatics.
\end{abstract}

Keywords: coccidiosis, Eimerias, anticoccidial drugs, coccidiostatics, chickens, Eimeria tenella, E. acervulina. 